\title{
Brain lesion locations associated with secondary seizure generalization
}

Janne Nordberg ${ }^{1,2}$, Frederic LWVJ. Schaper ${ }^{3}$, Marco Bucci ${ }^{4,5}$, Lauri Nummenmaa ${ }^{5}$, Juho Joutsa ${ }^{1,2,5,6}$

${ }^{1}$ Department of Clinical Neurophysiology, Turku University Hospital and University of Turku, Turku, Finland

${ }^{2}$ Turku Brain and Mind Center, Clinical Neurosciences, University of Turku, Turku, Finland

${ }^{3}$ Center for brain circuit therapeutics, Brigham and Women's Hospital and Harvard Medical

School, Boston, MA, USA

${ }^{4}$ Division of Clinical Geriatrics, Center for Alzheimer Research, Department of Neurobiology, Care Sciences and Society, Karolinska Institutet, Stockholm, Sweden

${ }^{5}$ Turku PET Centre, Turku University Hospital, Turku, Finland

${ }^{6}$ Neurocenter, Turku University Hospital, Turku, Finland

Correspondence:

Dr. Juho Joutsa

Turku Brain and Mind Center

Teutori building, $2^{\text {nd }}$ floor

20014 University of Turku

jtjout(a)utu.fi 
medRxiv preprint doi: https://doi.org/10.1101/2021.04.19.21255414; this version posted April 22, 2021. The copyright holder for this preprint

(which was not certified by peer review) is the author/funder, who has granted medRxiv a license to display the preprint in perpetuity.

All rights reserved. No reuse allowed without permission.

\begin{abstract}
Background: Structural brain lesions are the most common cause of adult-onset epilepsy. The lesion location may contribute to the risk for epileptogenesis, but whether specific lesion locations are associated with a risk for secondary seizure generalization from focal to bilateral tonic-clonic seizures, is unknown.
\end{abstract}

Methods: We identified patients with a diagnosis of adult-onset epilepsy caused by an ischemic stroke or a tumor diagnosed at the Turku University Hospital in 2004-2017. Lesion locations were segmented on patient-specific MR imaging and transformed to a common brain atlas (MNI space). Both region-of-interest analyses (intersection with the cortex, hemisphere, and lobes) and voxel-wise analyses were conducted to identify the lesion locations associated with focal to bilateral tonic-clonic compared to focal seizures.

Results: We included 170 patients with lesion-induced epilepsy (94 tumors, 76 strokes). Lesions predominantly localized in the cerebral cortex (OR 2.50, 95\% C.I. 1.21-5.15, p = 0.01) and right hemisphere (OR 2.22, 95\% C.I. 1.17-4.20, $p=0.01$ ) were independently associated with focal to bilateral tonic-clonic seizures. At the lobar-level, focal to bilateral tonic-clonic seizures were associated with lesions in the right frontal cortex (OR 4.41, 95\% C.I. 1.44-13.5, p =0.009). No single voxels were significantly associated with seizure type. These effects were independent of lesion etiology.

Conclusions: Our results demonstrate that lesion location is associated with the risk for secondary generalization of epileptic seizures independent of lesion etiology. These findings may contribute to identifying patients at risk for focal to bilateral tonic-clonic seizures. 
medRxiv preprint doi: https://doi.org/10.1101/2021.04.19.21255414; this version posted April 22, 2021. The copyright holder for this preprint

(which was not certified by peer review) is the author/funder, who has granted medRxiv a license to display the preprint in perpetuity.

All rights reserved. No reuse allowed without permission.

\section{Introduction}

Epilepsy is the fourth most common neurological disease, affecting more than 20 million people of all ages worldwide. ${ }^{1,2}$ Brain lesions are the most common cause of adult-onset epilepsy. ${ }^{3}$ Although almost all brain lesions can cause epilepsy, some types of lesions, such as infiltrating tumors, are more prone to cause epilepsy than other types, such as stroke. ${ }^{3,4}$ Clinical risk factors for lesion-induced epilepsy vary depending on the lesion etiology but on a patient level it's challenging to predict which lesions are likely to cause epilepsy and which are not. ${ }^{5,6}$

Lesion location has been suggested to play a role in the development of lesional epilepsy. ${ }^{4-6}$ In general, lesions in the cerebral cortex are associated with higher risk for epilepsy than lesions in other parts of the brain. ${ }^{4,5,7,8}$ In stroke, lesions in the anterior circulation area are associated with increased risk for late seizures and epilepsy compared to strokes in the posterior circulation. $^{5,7}$ In gliomas, tumor locations in the temporal and frontal lobe have been linked to an increased risk of seizures. However, there is no clear consensus between studies. ${ }^{4,8-10}$ Given that focal seizures can theoretically arise from any brain region, the lack of unifying brain region associated with epilepsy across lesion etiologies is not surprising.

Lesion-induced epilepsy is considered to cause focal epileptic activity, which in some patients spreads to other brain regions outside the focus and may eventually lead to bilateral tonicclonic seizures (focal to bilateral tonic-clonic, FTBTC). ${ }^{11}$ Secondary seizure generalization in FTBTC seizures involves cortical spreading of epileptic activity to both hemispheres and is hypothesized to include spread to subcortical brain regions including the thalamus, basal ganglia and cerebellum. ${ }^{12}$ However, the underlying mechanisms and pathways leading to FTBTC seizures are still unclear and it is not known if the anatomical lesion location plays a role in the generalization of seizures. ${ }^{13}$ FTBTC seizures are associated with a loss in quality of life ${ }^{2}$, a high risk of injury ${ }^{14}$, and an increased risk for sudden unexpected death in epilepsy (SUDEP). ${ }^{15}$ Identifying lesion locations associated with increased risk for FTBTC seizures may help to identify these patients at an early stage in treatment and benefit patient-specific epilepsy management. Moreover, characterizing lesion locations associated with FTBTC seizures may be valuable for understanding the mechanisms of secondary seizure generalization. ${ }^{11,16,17}$

The aim of this study was to investigate if lesion locations are associated with FTBTC seizures across stroke and astrocytoma, two common lesion etiologies associated with epilepsy. Using both a-priori-region of interest analyses and data-driven voxel-wise analyses, we compared lesion locations of patients FTBTC seizures to patients with focal seizures only. 
medRxiv preprint doi: https://doi.org/10.1101/2021.04.19.21255414; this version posted April 22, 2021. The copyright holder for this preprint

(which was not certified by peer review) is the author/funder, who has granted medRxiv a license to display the preprint in perpetuity.

All rights reserved. No reuse allowed without permission.

\section{Materials and methods}

\section{Patient selection}

Patients with lesion-induced epilepsy were identified from clinical records between 2004 and 2017 at Turku University Hospital, Turku, Finland. A systematic database search for patients with age $>/=18$ years with diagnosis of symptomatic epilepsy (International Classification of Diseases 10, ICD-10 codes: G40.00, G40.01, G40.09, G40.10, G40.11, G40.12, G40.19, G40.20, G40.21, G40.22 and G40.29) and brain MRI obtained up to +/- 3 months from the diagnosis of epilepsy was conducted. A relatively short interval between the epilepsy diagnosis and brain MRI was chosen to minimize the possibility of additional brain lesions or other confounding factors after the occurrence of the lesion. This search identified 1887 patients who were selected for a detailed clinical record review.

The case selection is illustrated in Figure 1. The clinical diagnoses and seizure types were retrieved from the hospital records. All epilepsy diagnoses were established at the department of neurology at the Turku University Hospital. All relevant clinical records including neuroimaging and clinical neurophysiology examination results and clinical follow up were carefully evaluated by the investigators. Out of 1887 cases evaluated, 748 were confirmed to have focal brain lesions and epilepsy according to the current International League Against Epilepsy (ILAE) definitions. ${ }^{18}$ To be able to address generalizability of the findings across lesion etiologies, we selected the two most common etiologies in our dataset into this study [astrocytoma $(n=201)$ and ischemic stroke $(n=134)$ ].

Stroke sample: The inclusion criteria were: (i) late seizures consistent with symptomatic epilepsy caused by an ischemic stroke, (ii) one or more ischemic focal stroke lesions in the MRI, (iii) no other brain lesions or structural abnormalities, (iv) no history of epileptic seizures prior to the stroke. Cases with diagnostic uncertainty whether they had focal-onset epilepsy or unclear etiology of epilepsy were excluded. In total, 76 patients fulfilled all criteria and were included in the study (Figure 1).

Tumor sample: The inclusion criteria were: (i) symptomatic epilepsy caused by an astrocytoma, (ii) one or more tumors with identifiable borders in the MRI, (iii) no other brain lesions or structural abnormalities, (iv) no history of epileptic seizures prior to the astrocytoma diagnosis. Cases with diagnostic uncertainty whether they had focal-onset epilepsy, unclear etiology of epilepsy or evidence of metastases were excluded. In total, 94 patients fulfilled the inclusion criteria (Figure 1). 
medRxiv preprint doi: https://doi.org/10.1101/2021.04.19.21255414; this version posted April 22, 2021. The copyright holder for this preprint (which was not certified by peer review) is the author/funder, who has granted medRxiv a license to display the preprint in perpetuity. All rights reserved. No reuse allowed without permission.

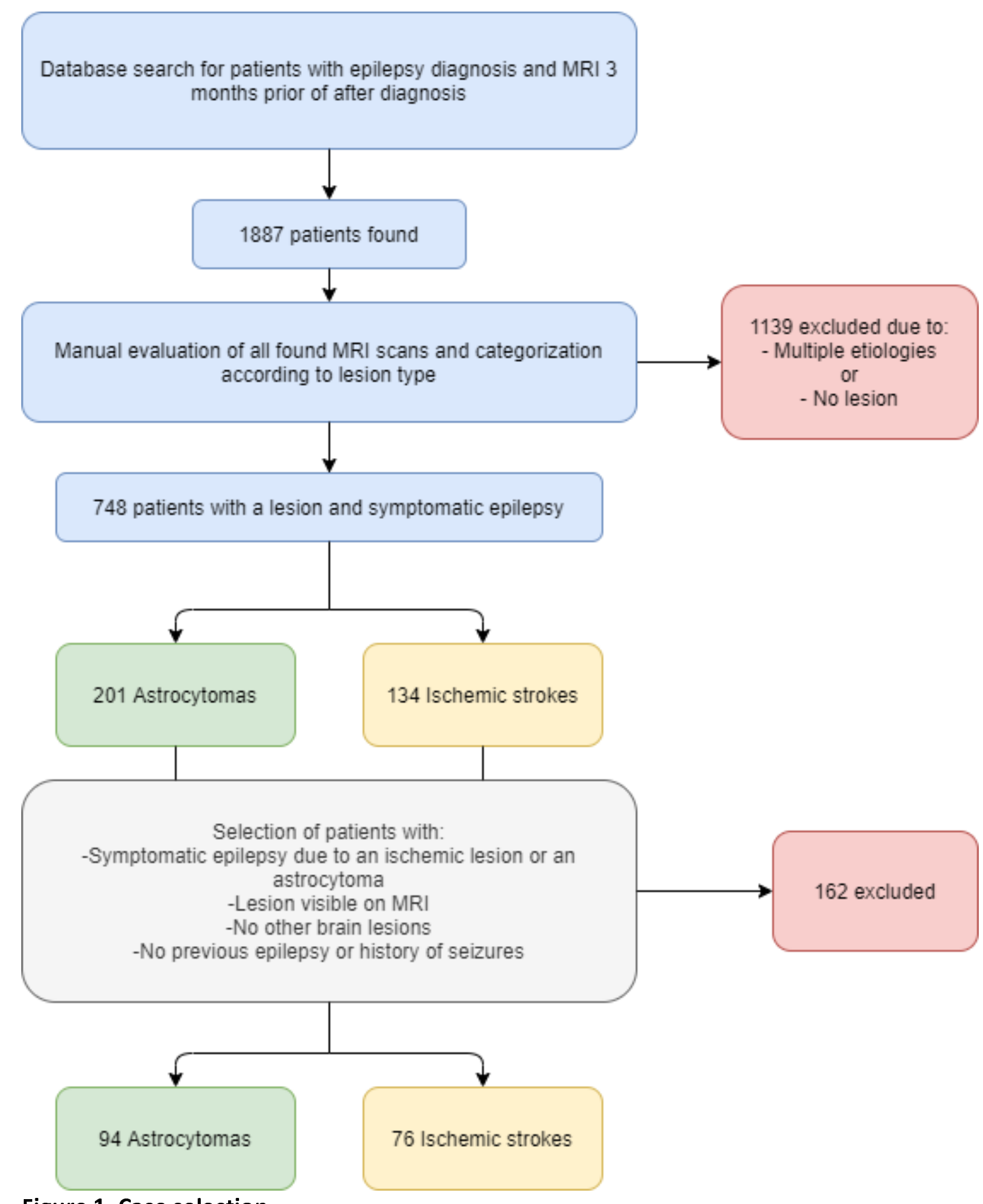

Figure 1. Case selection

\section{Clinical phenotyping}

Demographical and clinical data from the selected patients were obtained based on a detailed review of the medical records. Lesion etiology, gender, age at diagnosis, age at first seizure, age 
medRxiv preprint doi: https://doi.org/10.1101/2021.04.19.21255414; this version posted April 22, 2021. The copyright holder for this preprint

(which was not certified by peer review) is the author/funder, who has granted medRxiv a license to display the preprint in perpetuity.

All rights reserved. No reuse allowed without permission.

at occurrence of the lesion, seizure semiology, EEG findings, number of antiepileptic drugs (AEDs), presence of seizures at best AED therapy (in tumors before any surgery) and status epilepticus episodes were retrieved from the clinical records. In addition, tumor grade (I-IV) was extracted for patients with astrocytomas.

Time of occurrence of the lesion was defined as the time of first symptoms for stroke in the stroke sample and first brain scan showing the lesion in the tumor sample. The epilepsy types were classified to focal only (focal aware or focal impaired awareness), and FTBTC in accordance with the current ILAE classification. ${ }^{18,19}$

Lesions

Brain lesions were manually drawn on the high-resolution MR images in the subjects' native space using FSLeyes software [version 0.31.2, (Jenkinson et al., 2012)]. All slices in the T1 or T2w sequence were examined, and the lesion was approximated on each slice in all three planes. Non-lesioned voxels were assigned value 0 and lesioned voxels value 1 , producing a three-dimensional binary lesion mask. The individual MRI was then transformed to the MNI152 standard space using FMRIB's linear image registration tool (FLIRT) implemented in FSL. ${ }^{20-22}$ Nonlinear registration was not used because structural lesions may affect the gross brain anatomy, leading to bias when using other commonly used nonlinear transformations. Nearestneighbor interpolation was used to preserve dichotomous voxel classification (lesioned vs not lesioned voxels). The manually drawn lesion mask was registered to MNI152 standard space using the registration matrix obtained from the transformation of the anatomical image to MNI space. The alignment of the transformed images and resulting localization of the lesion in MNI space were manually inspected and edited to ensure accurate anatomical localization of the lesion. Lesion masks were used in both the region-of-interest analyses and voxel-wise analyses.

\section{Regions-of-interest}

A cerebral cortex mask was defined by combining all cortical regions in the Harvard-Oxford Cortical Structural Atlas with 0.25 threshold. ${ }^{23}$ Cortical involvement was evaluated by quantifying the number of lesion voxels intersecting with the cerebral cortex mask and dividing the number of cortical voxels with the total lesion volume. Lesions with at least half of the voxels located in the cerebral cortex were defined as predominantly cortical lesions. Lesion laterality was evaluated visually using the lesion masks. With bilaterally extending lesions, the hemisphere with the majority of voxels was defined as the predominant side of the lesion.

Lobar regions-of-interest (ROIs) were defined in the right and left hemisphere separately to the frontal, parietal, occipital and temporal lobe using the Harvard-Oxford Cortical Structural Atlas by combining all cortical subregions within each lobe. Lesioned voxels in each ROI were calculated and predominantly involved lobe was defined as the lobe with highest number of lesioned voxels.

Statistical analyses 
medRxiv preprint doi: https://doi.org/10.1101/2021.04.19.21255414; this version posted April 22, 2021. The copyright holder for this preprint

(which was not certified by peer review) is the author/funder, who has granted medRxiv a license to display the preprint in perpetuity.

All rights reserved. No reuse allowed without permission.

Differences in demographical and clinical characteristics between samples and epilepsy types were compared using independent samples t-test or Mann-Whitney U-test (continuous variables) and Chi-Square or Fisher Exact test (categorical variables), as appropriate.

Differences in lesion location (laterality and cortical involvement) between cases with focal vs FTBTC seizures in the whole sample were investigated using Chi-Square or Fisher Exact test, as appropriate. In addition, the degree of cortical involvement (percentage of the voxels located in the cerebral cortex) was compared between the groups using independent samples t-test. Finally, a binary logistic regression analysis with seizure type as the dependent variable, and predominant side, cortical involvement and lesion type as independent variables was conducted to study if these factors were independently associated with seizure generalization.

To localize the findings within the hemisphere at lobar-level, ROI analyses were conducted by comparing the number of voxels in each lobe between patients with focal only and FTBTC seizures. The significance of the difference was investigated using Mann-Whitney U tests because the highly skewed distribution of the numbers of voxels in each lobe. Bonferroni correction was used to control for increased type I error due to four lobes included in the analysis. The other hemisphere was used as a negative control to verify the hemispheric specificity of the findings. Independence of the total lesion size was investigated by repeating the analysis with percentages of voxels in an ROI of total lesion voxel, and independence of etiology by repeating the analysis in strokes and tumors separately. Finally, by comparing the proportions of patients with FTBTC seizures in patients with lesions predominantly involving the identified lobe vs. other brain regions using Fisher's Exact test, and the clinical relevance of the significant findings was quantified by calculating odds ratio for FTBTC seizures for the identified lobe compared to all other lesions using binary logistic regression controlling for lesion type.

\section{Voxel-based lesion symptom mapping}

Voxelwise lesion locations in patients with focal vs FTBTC seizures were compared using voxelbased lesion symptom mapping (VLSM) in both datasets combined. VLSM was conducted using NiiStat software (https://github.com.neurolabusc/NiiStat) according to the published recommendations. ${ }^{24}$ Lesion etiology and lesion size were used as nuisance covariates. The analyses were conducted across the whole brain in voxels affected in at least $5 \%(n \geq 9)$ of the cases and confirmed with thresholds of at least $10 \%(n \geq 17)$ and $n \geq 1$. Statistical significance was set at $\mathrm{P}<0.05$ corrected for family-wise error (FWE) using Freedman-Lane permutation with 2000 permutations. The main analysis was repeated in strokes and tumors separately to identify any etiology-dependent effects.

\section{Ethical statement}

The study protocol was approved by Turku University Hospital Clinical Research Services Board, and the study was conducted according to the principles of the Declaration of Helsinki. Due to the retrospective register-based nature of the clinical data collection and large sample size, the 
medRxiv preprint doi: https://doi.org/10.1101/2021.04.19.21255414; this version posted April 22, 2021. The copyright holder for this preprint (which was not certified by peer review) is the author/funder, who has granted medRxiv a license to display the preprint in perpetuity.

All rights reserved. No reuse allowed without permission.

need for separate ethical board review and obtaining written consent from the patients was waived.

\section{Data availability}

Voxelwise maps are available upon reasonable request. The original data cannot be made publicly available.

\section{Results}

\section{Demographics and lesions}

The demographical and clinical data of the lesion samples are presented in Table 1. There were no differences in the proportion of patients with FTBTC seizures between etiologies (Table 1). In patients with focal seizures only, seizures with impaired awareness were more common in strokes compared to tumors (Table 1). Focal slowing in EEG was more common in strokes compared to tumors (Table 1). Stroke patients were older and had a longer delay between the discovery of the lesion and onset of seizures compared to tumor patients (Table 1).

Table 1. Demographical and clinical data

\begin{tabular}{|c|c|c|c|c|}
\hline & Total $(n=170)$ & Tumors $(n=94)$ & Strokes $(n=76)$ & p-value \\
\hline Sex (Male:Female) & $89: 81$ & $50: 44$ & $39: 37$ & 0.88 \\
\hline Age at Diagnosis (y) & $55.9(17.0)$ & $47.8(15.9)$ & $65.9(13.1)$ & $<0.001$ \\
\hline Age at First seizure (y) & $54.4(17.0)$ & $47.1(16.0)$ & $63.3(13.7)$ & $<0.001$ \\
\hline Age at Lesion discovery (y) & $53.0(17.0)$ & $47.1(16.1)$ & $61.0(14.6)$ & $<0.001$ \\
\hline Delay from Lesion to seizure (days) & $462(1490)$ & $127(612)$ & $978(2162)$ & $<0.001$ \\
\hline \multicolumn{5}{|l|}{ Seizure type } \\
\hline FTBTC seizures & $102(60.0 \%)$ & $57(60.6 \%)$ & $45(59.2 \%)$ & 0.88 \\
\hline Focal seizures only & $68(40.9 \%)$ & $37(39.4 \%)$ & $31(40.8 \%)$ & \\
\hline ...Focal aware & $41(24.1 \%)$ & $30(31.9 \%)$ & $11(14.5 \%)$ & $<0.001$ \\
\hline ...Focal impaired awareness & $27(15.9 \%)$ & $7(7.4 \%)$ & $20(26.3 \%)$ & \\
\hline \multicolumn{5}{|l|}{ EEG finding } \\
\hline Normal & $52(30.6 \%)$ & $29(30.9 \%)$ & $23(30.3 \%)$ & 0.01 \\
\hline Epileptiform & $35(20.6 \%)$ & $10(10.6 \%)$ & $25(32.9 \%)$ & \\
\hline Focal slowing & $49(28.8 \%)$ & $29(30.9 \%)$ & $20(26.3 \%)$ & \\
\hline NA & $34(20.0 \%)$ & $26(27.7 \%)$ & $8(10.5 \%)$ & \\
\hline \multicolumn{5}{|l|}{ Status epilepticus at any time } \\
\hline No & $145(85.3 \%)$ & $84(89.4 \%)$ & $61(80.3 \%)$ & 0.10 \\
\hline Yes & $25(14.7 \%)$ & $10(10.6 \%)$ & $15(19.7 \%)$ & \\
\hline
\end{tabular}


medRxiv preprint doi: https://doi.org/10.1101/2021.04.19.21255414; this version posted April 22, 2021. The copyright holder for this preprint (which was not certified by peer review) is the author/funder, who has granted medRxiv a license to display the preprint in perpetuity.

All rights reserved. No reuse allowed without permission.

\begin{tabular}{lllll} 
None & $45(26.5 \%)$ & $30(31.9 \%)$ & $15(19.7 \%)$ & 0.10 \\
Yes & $122(71.8 \%)$ & $64(68.1 \%)$ & $58(76.3 \%)$ & \\
NA & $3(1.8 \%)$ & $0(0.0 \%)$ & $3(3.9 \%)$ & \\
Number of AEDs in use & & & & 0.43 \\
None & $2(1.2 \%)$ & $0(0.0 \%)$ & $2(2.6 \%)$ & \\
1 & $152(89.4 \%)$ & $86(91.5 \%)$ & $66(86.8 \%)$ & \\
2 & $14(8.2 \%)$ & $7(7.4 \%)$ & $7(9.2 \%)$ & \\
3 & $3(2.0 \%)$ & $1(1.1 \%)$ & $1(1.3 \%)$ & \\
\hline
\end{tabular}

Mean (SD) or number of subjects (proportion of the respective sample) are shown in the table. $A E D=$ antiepileptic drug. NA = not available. FTBTC = focal to bilateral tonic-clonic.

Lesion locations were heterogeneously distributed across the brain (Figure 2A) with tumors preferentially localizing to the basal ganglia, insula, temporal lobes and frontal lobes (Figure 2B), and strokes to the regions supplied by the middle cerebral artery (Figure 2C).

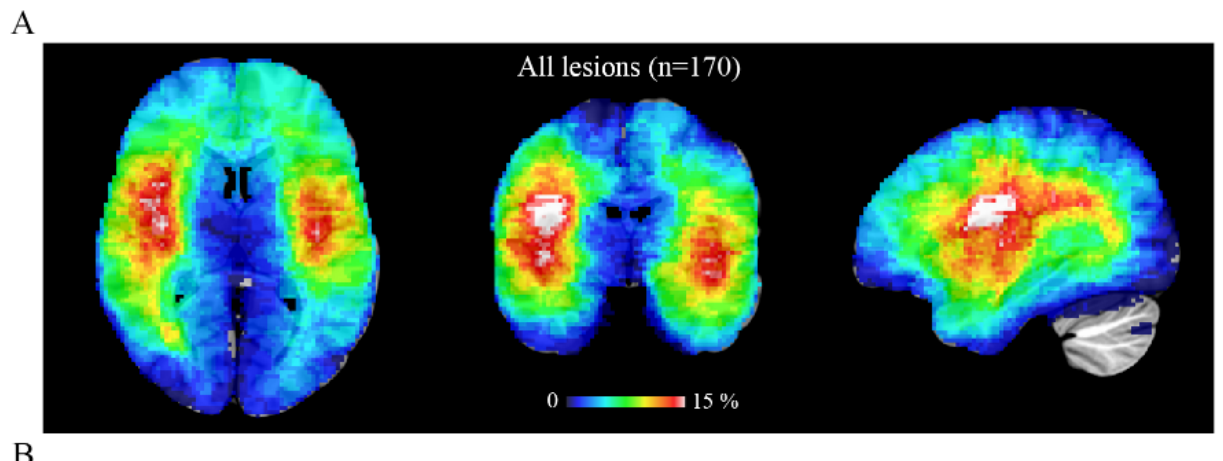

B

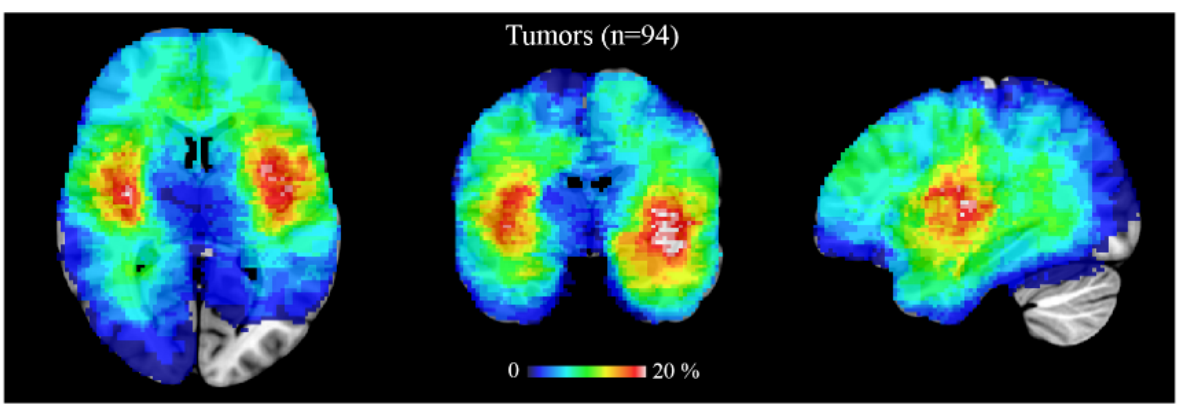

$\mathrm{C}$

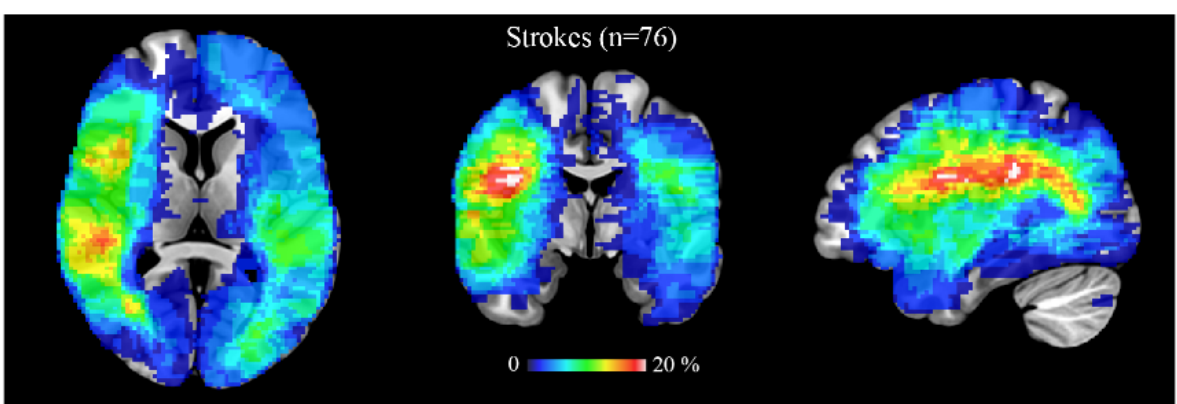

Figure 2. Lesion overlap 
Lesion overlap in A) the whole sample ( $n=170), B)$ tumor sample $(n=94)$ and C) stroke sample $(n=76)$. The maximum overlap of lesions at any voxel was $18.8 \%, 28.7 \%$ and $23.6 \%$ of the sample, respectively.

Patients with FTBTC seizures were slightly younger compared to patients with focal seizures only but there were no other significant differences between the groups in demographic or clinical characteristics (Table 2). Demographic data according to the seizure type for the stroke and tumor samples separately are available in the supplementary material (Table S1 and S2, respectively).

Table 2. Demographic and clinical data according to the seizure type

\begin{tabular}{llll}
\hline & Focal $(\mathrm{n}=68)$ & FTBTC $(\mathrm{n}=102)$ & $\mathrm{p}$-value \\
\hline Sex (Male:Female) & $37: 31$ & $57: 45$ & 0.49 \\
Age at Diagnosis $(\mathrm{y})$ & $58.5(16.2)$ & $55.1(17.8)$ & 0.11 \\
Age at First seizure $(\mathrm{y})$ & $57.0(16.1)$ & $52.6(17.5)$ & 0.09 \\
Age at Lesion discovery $(\mathrm{y})$ & $56.4(16.2)$ & $50.7(17.2)$ & 0.04 \\
Delay from Lesion to seizure (days) & $245(773)$ & $595(1785)$ & 0.73
\end{tabular}

\section{Lesion type}

Tumor

Stroke

Lesion characteristics

Size $\left(\mathrm{cm}^{3}\right)$

Laterality (right-sided)

Cortical

\section{EEG finding}

Normal

Epileptiform

Focal slowing

NA

Status epilepticus at any time

No

Yes

Seizures on best AED therapy

None

Yes

NA

Number of AEDs in use

None
$37(54.4 \%)$

57 (55.9\%)

0.87

31 (45.6\%)

45 (44.1\%)

72.1 (73.9)

$79.8(85.2)$

0.54

$28(41.2 \%)$

$61(59.8 \%)$

0.02

$44(65.7 \%)$

$83(81.4 \%)$

0.02

$\begin{array}{ll}21 \text { (30.9\%) } & 31 \text { (30.4\%) } \\ 17(25.0 \%) & 18(17.6 \%) \\ 17(25.0 \%) & 32(31.4 \%) \\ 13(19.1 \%) & 21(20.6 \%)\end{array}$

$61(89.7 \%)$

$84(82.4 \%)$

0.27

$7(10.3 \%)$

$18(17.6 \%)$

$\begin{array}{ll}30(31.9 \%) & 15(19.7 \%) \\ 64(68.1 \%) & 58(76.3 \%) \\ 0(0.0 \%) & 3(3.9 \%)\end{array}$

$2(2.9 \%)$

0 (0.0\%)

0.25 
medRxiv preprint doi: https://doi.org/10.1101/2021.04.19.21255414; this version posted April 22, 2021. The copyright holder for this preprint (which was not certified by peer review) is the author/funder, who has granted medRxiv a license to display the preprint in perpetuity.

All rights reserved. No reuse allowed without permission.

1

2

3

Mean (SD) or number of subjects (proportion of the respective sample) are shown in the table. $A E D=$ antiepileptic drug. NA = not available. FTBTC = focal to bilateral tonic-clonic.

\section{Regions-of-interest analyses}

FTBTC seizures were more common in patients with lesions predominantly localized to the cerebral cortex compared to subcortical lesions ( $65.3 \%$ vs $44.2 \%, p=0.01$, Figure $3 \mathrm{~A})$, and the right hemisphere compared to the left (68.5\% vs $50.6 \%, p=0.02$, Figure 3B). The mean (SD) proportion of voxels of the lesion in the cerebral cortex was $62.0 \%(19.8)$ in lesions associated with FTBTC seizures and $54.9 \%$ (22.7) in lesions associated with focal seizures only $(p=0.03)$. The laterality effect remained significant when excluding 21 patients with bilateral lesions from the analysis $(68.3 \%$ vs $51.4 \%, p=0.04)$. In the logistic regression analysis, both predominantly cortical (OR 2.50, 95\% C.I. 1.21-5.15, $p=0.01$ ) and right-sided lesions (OR 2.22, 95\% C.I. 1.17$4.20, p=0.01)$ were independently associated with FTBTC seizures, while lesion etiology was not $(p=1.0)$. There were no significant interaction effects between predominantly cortical lesion location, lesion laterality and cortical involvement. Adding age at lesion discovery to the regression model did not change the significance of the effects. There were also no differences in the proportion of predominantly cortical $(79.6 \%$ vs $69.7 \%, p=0.14)$ or right-sided lesions $51.1 \%$ vs $53.9 \%, p=0.71$ ) between tumors and strokes.

In the lobar ROI analyses, lesions associated with FTBTC seizures involved the right frontal cortex more than lesions associated with focal seizures only [median (IQR) voxels: 781 (4-3386) vs. $416(0-1929), p=0.007$, corrected $p=0.03)$. There were no significant differences between the seizure types in other lobes in the right or in any of the lobes in the left hemisphere. The involvement of the right frontal lobe was also significant when accounting for lesion size $(p=0.006)$, and when analyzing strokes $(p=0.048)$ and tumors $(p=0.03)$ separately]. Lesions predominantly located in the right frontal cortex were associated with FTBTC seizures (OR 4.41, $95 \%$ C.I. 1.44-13.5, $p=0.009)$ compared to lesions located in other regions independent of lesion etiology $(p=0.96)$ (Figure $3 C)$. There also was no significant interaction effect between lesion type and location in the right frontal cortex $(p=0.46)$.

Voxel-based lesion symptom mapping

The results from the voxelwise VLSM analyses showed clear right-laterization of lesion locations associated with FTBTC seizures (Figure 3D, Figure S1). However, the VLSM analysis did not identify any single voxels significantly associated with FTBTC seizures (Figure 3D). 
medRxiv preprint doi: https://doi.org/10.1101/2021.04.19.21255414; this version posted April 22, 2021. The copyright holder for this preprint (which was not certified by peer review) is the author/funder, who has granted medRxiv a license to display the preprint in perpetuity.

All rights reserved. No reuse allowed without permission.
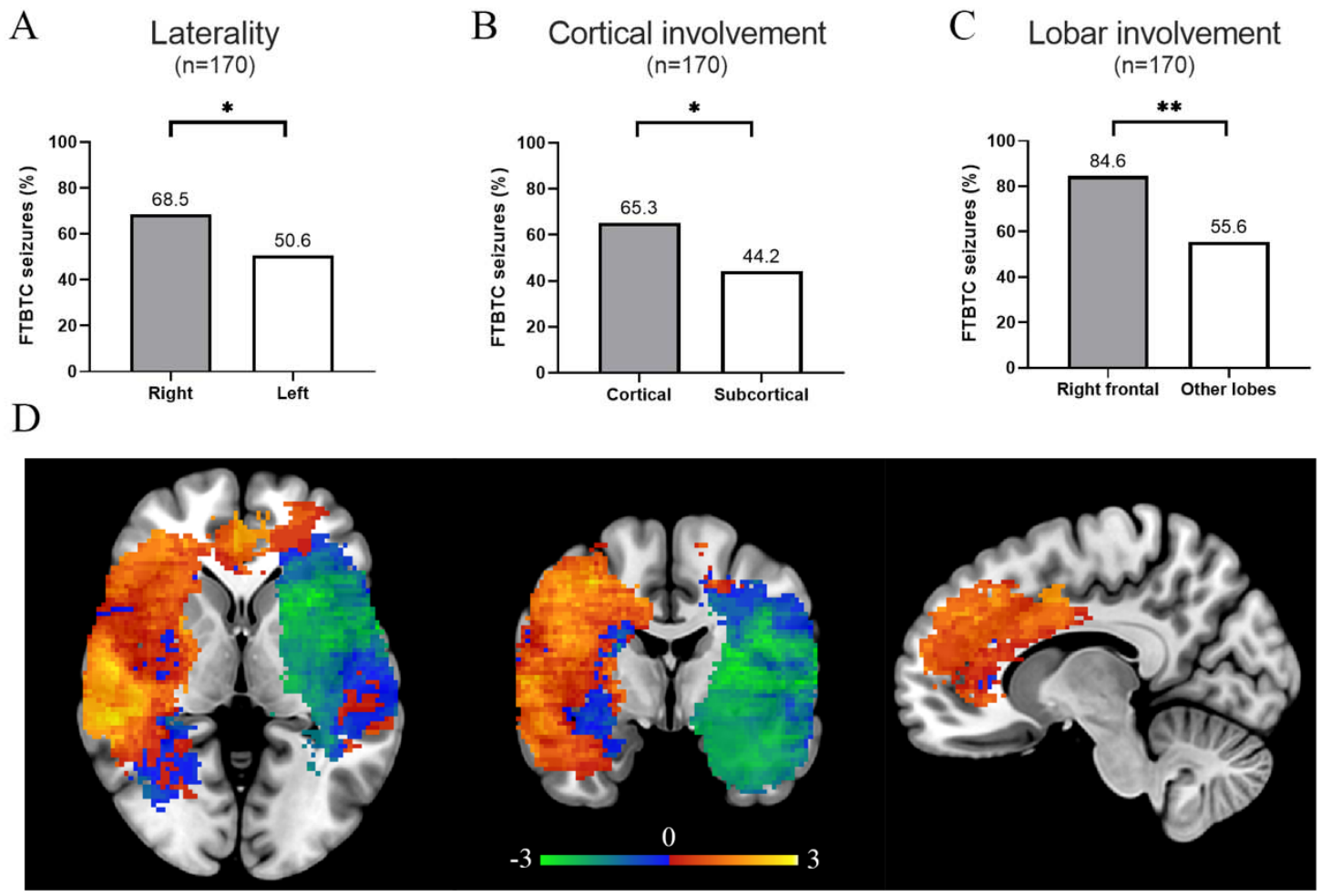

Figure 3. Lesion locations associated with focal to bilateral tonic-clonic (FTBTC) seizures Proportion of patients with FTBTC seizures according to the predominant side of the lesion (A), predominantly cortical / subcortical lesion location, and involvement of the right frontal lobe (C). Voxel-lesion symptom mapping (VLSM) z map showing brain regions associated with FTBTC seizures (red-yellow scale) and focal seizures (bluegreen scale) (D). The sagittal section is from the right hemisphere. There were no voxels significantly associated with the seizure type when corrected for multiple comparisons in the whole search volume.

\section{Discussion}

The main finding of the present study is that lesion location is associated with secondary generalization of focal seizures (FTBTC seizures). Specifically, cortical lesions, lesions in the right hemisphere and right frontal lobe are associated with an increased risk for FTBTC seizures. These effects were independent of lesion etiology. However, lesion associated with FTBTC seizures did not localize to any single anatomical region within the right frontal cortex, which is in agreement with the current views that seizure generalization is a multifactorial process involving widespread brain regions rather than localized to a single hub in the brain. ${ }^{11,12}$

Previous lesion mapping studies in epilepsy have mainly focused on identification of clinical risk factors for epilepsy and crude anatomical localization of brain regions associated with seizures and epilepsy. ${ }^{5,7,25}$ Across etiologies, there is consensus that lesions in the cerebral cortex are associated with a higher risk for epileptic seizures compared to subcortical lesions, e.g. basal ganglia and cerebellum. ${ }^{4,5,7,8}$ In stroke, lesions in the anterior circulation are associated with increased late seizure risk but result of more detailed localization into which lobes are associated with an increased risk for late seizure have been negative or inconsistent between 
medRxiv preprint doi: https://doi.org/10.1101/2021.04.19.21255414; this version posted April 22, 2021. The copyright holder for this preprint (which was not certified by peer review) is the author/funder, who has granted medRxiv a license to display the preprint in perpetuity. All rights reserved. No reuse allowed without permission.

studies. ${ }^{26-30}$ Studies investigating seizure risk in brain tumors have linked increased seizure risk to varying brain regions, including the medial temporal and frontal lobes. ${ }^{6,8-10}$ However, there doesn't seem to be consistent evidence on which brain regions are most susceptible for the development of lesion-induced epileptic seizures across etiologies.

The present study focused on identifying lesion locations associated with secondary seizure generalization rather than epileptic seizures per se. Our results show that cortical lesions increase the risk for FTBTC seizures, adding to the current knowledge that cortical lesions are more prone to cause any type of seizures. ${ }^{5,7,25}$ Cortical lesions could contribute to the risk of seizure generalization in multiple ways. Greater lesion burden in the cerebral cortex may increase the amount of brain tissue with reduced seizure threshold, causing more widespread or multifocal discharges, or making it easier for epileptic activity to spread from cortical region to another, eventually leading to secondary generalization to FTBTC seizures. ${ }^{12,31}$ Cortical lesions may also lead to a disconnection and loss of cortical control over spontaneous oscillations of subcortical hubs, such as the thalamus, which is known to generate synchronous abnormal neuronal activity in generalized seizures. ${ }^{11,12,32,33}$

Lesion location in the right hemisphere was another independent risk factor for FTBTC seizures in the present study. While previously reported in the literature, the reason for increased risk for secondary generalization of seizures with right hemisphere lesions is not clear. Our finding is in agreement with earlier evidence of right-sided stroke lesions associated with an increased risk for late seizures. ${ }^{30}$ It has been suggested that the left hemisphere may have lower seizure threshold compared to the right hemisphere. ${ }^{34}$ While we can only speculate on this, seizure generalization to the contralateral hemisphere may occur more easily in patients with lesion induced epilepsy originating from the, "less-epileptogenic", right sided hemisphere. Seizure generalization from the left hemisphere to the right hemisphere may be less frequent, due to the higher seizure threshold for the right hemisphere. Our findings also indicate that lesion location in the right frontal cortex may carry a particularly high risk for secondary generalization. However, similarly to many other studies ${ }^{6,9,26-30,35}$, we did not identify any single common hub that, when lesioned, would be significantly associated with epileptic seizures. There are only very few previous studies analyzing the lesion location in a voxel-wise manner and comparing patients with FTBTC to focal seizures. The results from these studies indicate that gliomas involving the corpus callosum ${ }^{13}$ or premotor cortex ${ }^{8}$ could increase risk for FTBTC seizures, but these findings have not been replicated or confirmed in other studies including the present study.

Patients with FTBTC seizures were slightly younger compared to patients with focal seizures only. This is in line with previous observations that younger age is associated with increased risk for late-onset seizures ${ }^{5}$ and could be explained by slow neuroplastic changes, which are known to be more pronounced in younger individuals. ${ }^{36}$ However, age was not independently associated with seizure generalization in the present study and adding age to the regression model did not change the significance of the lesion laterality or cortical location effects. 
medRxiv preprint doi: https://doi.org/10.1101/2021.04.19.21255414; this version posted April 22, 2021. The copyright holder for this preprint

(which was not certified by peer review) is the author/funder, who has granted medRxiv a license to display the preprint in perpetuity.

All rights reserved. No reuse allowed without permission.

The strengths of the present study include a focus on seizure generalization and detailed lesion localization by only including patients with high-quality, modern brain MRI with a clearly identifiable focal lesions without mass effects. The analyses were conducted by using several approaches, including a region of interest analyses of crude lesion localization (corticalsubcortical, right-left hemisphere, lobes) and a whole brain voxelwise analysis to identify specific brain regions. Our study was also not restricted to single lesion etiology but included two clinically different lesion types to identify brain regions, which could be important for secondary generalization across etiologies.

There are however some limitations that should be considered when interpreting the results of the present study. First, although our findings indicate that lesion-based localization of FTBTC seizures are independent on lesion etiology, our analyses were limited two lesion types (ischemic strokes, astrocytomas). To what extent these findings generalize to other etiologies, remains to be investigated in subsequent studies. Second, although all of our cases were diagnosed at a university hospital and carefully re-evaluated by the investigators, due to the retrospective nature of the study, it is possible that the clinical characterization of the epilepsy is incorrect in some patients. For example, patients may not report FTBTC seizures because of fearing losing a job or driver's license. However, incorrect characterization of seizures would lead to increased noise in the data and bias us against the present findings indicating that lesion location is associated with FTBTC seizures. Finally, it is possible that our sample size may not have been sufficient to identify associations between lesions to individual brain regions and seizure generalization. However, if present, such weak associations are likely to have only limited significance in clinical practice.

In conclusion, brain lesions localizing to the cerebral cortex and the right hemisphere are associated with increased risk for secondary seizure generalization in patients with lesioninduced epilepsy. Our findings further suggest that lesions in the right frontal cortex may be particularly susceptible for development of FTBTC seizures. These findings can help to better identify patients at risk for FTBTC seizures. 
medRxiv preprint doi: https://doi.org/10.1101/2021.04.19.21255414; this version posted April 22, 2021. The copyright holder for this preprint (which was not certified by peer review) is the author/funder, who has granted medRxiv a license to display the preprint in perpetuity.

\section{Acknowledgements}

None.

\section{Conflicts of interest}

The authors report no relevant conflicts of interest.

\section{Financial disclosure}

$J N, M B$ and $L N$ have nothing to report. JJ has received research funding from the Finnish Foundation for Alcohol Studies, Finnish Medical Foundation, Finnish Parkinson Foundation, University of Turku and Turku University Hospital (VTR funding), and lecturer honorarium from Lundbeck.

\section{References}

1. Fiest KM, Sauro KM, Wiebe $S$, et al. Prevalence and incidence of epilepsy: A systematic review and meta-analysis of international studies. Neurology. Jan 2017;88(3):296-303. doi:10.1212/WNL.0000000000003509

2. Collaborators GE. Global, regional, and national burden of epilepsy, 1990-2016: a systematic analysis for the Global Burden of Disease Study 2016. Lancet Neurol. 04 2019;18(4):357-375. doi:10.1016/S1474-4422(18)30454-X

3. Thurman DJ, Faught E, Helmers S, Kim H, Kalilani L. New-onset lesional and nonlesional epilepsy in the US population: Patient characteristics and patterns of antiepileptic drug use. Epilepsy Res. 11 2019;157:106210. doi:10.1016/j.eplepsyres.2019.106210

4. Kerkhof $\mathrm{M}$, Vecht $\mathrm{CJ}$. Seizure characteristics and prognostic factors of gliomas. Epilepsia. Dec 2013;54 Suppl 9:12-7. doi:10.1111/epi.12437

5. Pitkänen A, Roivainen R, Lukasiuk K. Development of epilepsy after ischaemic stroke. Lancet Neurol. 02 2016;15(2):185-197. doi:10.1016/S1474-4422(15)00248-3

6. Chang EF, Potts MB, Keles GE, et al. Seizure characteristics and control following resection in 332 patients with low-grade gliomas. J Neurosurg. Feb 2008;108(2):227-35. doi:10.3171/JNS/2008/108/2/0227

7. Zhang $C$, Wang $X$, Wang $Y$, et al. Risk factors for post-stroke seizures: a systematic review and meta-analysis. Epilepsy Res. Dec 2014;108(10):1806-16. doi:10.1016/j.eplepsyres.2014.09.030

8. Wang Y, Qian T, You G, et al. Localizing seizure-susceptible brain regions associated with low-grade gliomas using voxel-based lesion-symptom mapping. Neuro Oncol. Feb 2015;17(2):282-8. doi:10.1093/neuonc/nou130

9. Lee JW, Wen PY, Hurwitz S, et al. Morphological characteristics of brain tumors causing seizures. Arch Neurol. Mar 2010;67(3):336-42. doi:10.1001/archneurol.2010.2

10. Cayuela N, Simó M, Majós C, et al. Seizure-susceptible brain regions in glioblastoma: identification of patients at risk. Eur J Neurol. 02 2018;25(2):387-394. doi:10.1111/ene.13518 
medRxiv preprint doi: https://doi.org/10.1101/2021.04.19.21255414; this version posted April 22, 2021. The copyright holder for this preprint (which was not certified by peer review) is the author/funder, who has granted medRxiv a license to display the preprint in perpetuity.

All rights reserved. No reuse allowed without permission.

11. Brodovskaya A, Kapur J. Circuits generating secondarily generalized seizures. Epilepsy Behav. 12 2019;101(Pt B):106474. doi:10.1016/j.yebeh.2019.106474

12. Blumenfeld $\mathrm{H}$, Varghese GI, Purcaro MJ, et al. Cortical and subcortical networks in human secondarily generalized tonic-clonic seizures. Brain. Apr 2009;132(Pt 4):999-1012. doi:10.1093/brain/awp028

13. Wieshmann UC, Milinis K, Paniker J, et al. The role of the corpus callosum in seizure spread: MRI lesion mapping in oligodendrogliomas. Epilepsy Res. Jan 2015;109:126-33. doi:10.1016/j.eplepsyres.2014.10.023

14. Lawn ND, Bamlet WR, Radhakrishnan K, O'Brien PC, So EL. Injuries due to seizures in persons with epilepsy: a population-based study. Neurology. Nov 2004;63(9):1565-70. doi:10.1212/01.wnl.0000142991.14507.b5

15. Devinsky O, Hesdorffer DC, Thurman DJ, Lhatoo S, Richerson G. Sudden unexpected death in epilepsy: epidemiology, mechanisms, and prevention. Lancet Neurol. 09 2016;15(10):1075-88. doi:10.1016/S1474-4422(16)30158-2

16. Langan Y, Nashef L, Sander JW. Case-control study of SUDEP. Neurology. Apr 2005;64(7):1131-3. doi:10.1212/01.WNL.0000156352.61328.CB

17. Hesdorffer DC, Tomson T, Benn E, et al. Combined analysis of risk factors for SUDEP. Epilepsia. Jun 2011;52(6):1150-9. doi:10.1111/j.1528-1167.2010.02952.x

18. Fisher RS, Cross JH, French JA, et al. Operational classification of seizure types by the International League Against Epilepsy: Position Paper of the ILAE Commission for Classification and Terminology. Epilepsia. 04 2017;58(4):522-530. doi:10.1111/epi.13670

19. Scheffer IE, Berkovic S, Capovilla G, et al. ILAE classification of the epilepsies: Position paper of the ILAE Commission for Classification and Terminology. Epilepsia. 04 2017;58(4):512521. doi:10.1111/epi.13709

20. Jenkinson $M$, Bannister $P, B$ Bady $M$, Smith S. Improved optimization for the robust and accurate linear registration and motion correction of brain images. Neuroimage. Oct 2002;17(2):825-41. doi:10.1016/s1053-8119(02)91132-8

21. Jenkinson $M$, Smith $S$. A global optimisation method for robust affine registration of brain images. Med Image Anal. Jun 2001;5(2):143-56. doi:10.1016/s1361-8415(01)00036-6 22. Greve DN, Fischl B. Accurate and robust brain image alignment using boundary-based registration. Neuroimage. Oct 2009;48(1):63-72. doi:10.1016/j.neuroimage.2009.06.060

23. Desikan RS, Ségonne F, Fischl B, et al. An automated labeling system for subdividing the human cerebral cortex on MRI scans into gyral based regions of interest. Neuroimage. Jul 2006;31(3):968-80. doi:10.1016/j.neuroimage.2006.01.021

24. Karnath $\mathrm{HO}$, Sperber $\mathrm{C}$, Rorden $\mathrm{C}$. Mapping human brain lesions and their functional consequences. Neuroimage. Oct 2017;165:180-189. doi:10.1016/j.neuroimage.2017.10.028

25. Camilo O, Goldstein LB. Seizures and epilepsy after ischemic stroke. Stroke. Jul 2004;35(7):1769-75. doi:10.1161/01.STR.0000130989.17100.96

26. Bladin CF, Alexandrov AV, Bellavance A, et al. Seizures after stroke: a prospective multicenter study. Arch Neurol. Nov 2000;57(11):1617-22. doi:10.1001/archneur.57.11.1617 27. Lamy C, Domigo V, Semah F, et al. Early and late seizures after cryptogenic ischemic stroke in young adults. Neurology. Feb 2003;60(3):400-4. doi:10.1212/wnl.60.3.400 
medRxiv preprint doi: https://doi.org/10.1101/2021.04.19.21255414; this version posted April 22, 2021. The copyright holder for this preprint (which was not certified by peer review) is the author/funder, who has granted medRxiv a license to display the preprint in perpetuity.

All rights reserved. No reuse allowed without permission.

28. Leone MA, Tonini MC, Bogliun G, et al. Risk factors for a first epileptic seizure after stroke: a case control study. J Neurol Sci. Feb 2009;277(1-2):138-42.

doi:10.1016/j.jns.2008.11.004

29. Heuts-van Raak L, Lodder J, Kessels F. Late seizures following a first symptomatic brain infarct are related to large infarcts involving the posterior area around the lateral sulcus. Seizure. Sep 1996;5(3):185-94. doi:10.1016/s1059-1311(96)80034-3

30. Galovic M, Döhler N, Erdélyi-Canavese B, et al. Prediction of late seizures after ischaemic stroke with a novel prognostic model (the SeLECT score): a multivariable prediction model development and validation study. Lancet Neurol. 02 2018;17(2):143-152. doi:10.1016/S14744422(17)30404-0

31. Schindler K, Leung H, Lehnertz K, Elger CE. How generalised are secondarily "generalised" tonic clonic seizures? J Neurol Neurosurg Psychiatry. Sep 2007;78(9):993-6. doi:10.1136/jnnp.2006.108753

32. Fogerson PM, Huguenard JR. Tapping the Brakes: Cellular and Synaptic Mechanisms that Regulate Thalamic Oscillations. Neuron. Nov 2016;92(4):687-704. doi:10.1016/j.neuron.2016.10.024

33. Paz JT, Davidson TJ, Frechette ES, et al. Closed-loop optogenetic control of thalamus as a tool for interrupting seizures after cortical injury. Nat Neurosci. Jan 2013;16(1):64-70. doi:10.1038/nn.3269

34. Holmes MD, Dodrill CB, Kutsy RL, Ojemann GA, Miller JW. Is the left cerebral hemisphere more prone to epileptogenesis than the right? Epileptic Disord. Sep 2001;3(3):13741.

35. Wang W, Yu J, Liu Y, et al. Voxel-based meta-analysis of grey matter changes in Alzheimer's disease. Translational Neurodegenration. 2015;4(6):eCollection 2015. doi:doi: 10.1186/s40035-015-0027-z

36. Wolpaw JR. Harnessing neuroplasticity for clinical applications. Brain. Apr 2012;135(Pt 4):e215; author reply e216. doi:10.1093/brain/aws017 